\title{
Quality of life in tai chi chuan practitioners in regions of Brazil
}

Qualidade de vida de praticantes de tai chi chuan em regiões do Brasil

\author{
H. Almeida Júnior ${ }^{1,2 *}$; E. K. Karasawa2 ; T. M. A. Rodrigues ${ }^{3}$; A. G. da Silva ${ }^{5,6}$; A. \\ A. Bastos ${ }^{1,7}$; M. B. de Almeida ${ }^{1,4,7}$; M. M. V. de Bragança ${ }^{7}$; R. C. do Nascimento ${ }^{7}$; \\ M. C. Haiachi ${ }^{7}$ \\ ${ }^{1}$ Programa de Pós-graduação em Educação Física, Universidade Federal de Sergipe, 49100-000, São Cristóvão- \\ Sergipe, Brasil \\ ${ }^{2}$ Sociedade Brasileira de Tai Chi Chuan e Cultura Oriental - Núcleo Aracaju,49050-660, Aracaju-Sergipe, Brasil \\ ${ }^{3}$ Departamento de Morfologia, Universidade Federal de Sergipe, 49100-000, São Cristóvão-Sergipe, Brasil \\ ${ }^{4}$ L'Esporte - Laboratório de Estudo e Pesquisa em Performance no Exercício e no Esporte, Universidade Federal de \\ Sergipe, 49100-000, São Cristóvão-Sergipe, Brasil \\ ${ }^{5}$ Seção de Educação Física, Escola Preparatória de Cadetes do Ar, 36205-058, Barbacena-Minas Gerais, Brasil \\ ${ }^{6}$ Departamento de Educação Física, Universidade Federal de Viçosa, 36570-000, Viçosa-Minas Gerais, Brasil \\ ${ }^{7}$ Departamento de Educação Física, Universidade Federal de Sergipe, 49100-000, São Cristóvão-Sergipe, Brasil
}

*heleno.taichi@gmail.com

(Recebido em 14 de julho de 2020; aceito em 25 de setembro de 2020)

\begin{abstract}
In Brazil, the supportive scientific evidence along with the increasing Tai Chi Chuan (TCC) popularity has contributed to its current insertion in the complementary integrative practices of the Brazilian Unified Health System. This study aimed to analyze the quality of life in TCC practitioners in several Brazilian cities, to compare the quality of life among cities and between genders, and to investigate if the TCC practice time interferes with the quality of life. The sample consisted of 104 individuals (69 women) who reported regular practice of Yang style TCC at least twice a week for a minimum period of three months. The sample was $50.3 \pm 15.4$ years old, with practice time of $74.8 \pm 50.3$ months. We classified the participants as beginners (3-12 months; $\mathrm{n}=42)$, intermediate (12-24 months; $\mathrm{n}=17)$, and advanced (> 24 months; $\mathrm{n}=45)$. The participants answered the Short Form Health Survey (SF-36) questionnaire (Portuguese version) to obtain a measure of quality of life. Based on the results, the practitioners were classified in the SF-36 as "good" and "very good", with higher scores found in men vs women. Quality of life scores observed were similar among all levels and cities. The health domain that obtained the highest overall score was functional capacity with $89.42 \pm 12.21$, and the lowest one was the general health status with $66.94 \pm 18.08$. This is corroborated by international scientific literature, with emphasis on the regular practitioners' quality of life.

Keywords: tai chi chuan, quality of life, complementary integrative practices.
\end{abstract}

No Brasil, as evidências científicas de suporte, juntamente com a crescente popularidade do Tai Chi Chan (TCC), contribuíram para sua inserção atual nas práticas integrativas complementares do Sistema Único de Saúde. Este estudo analisou a qualidade de vida de praticantes de TCC em várias cidades brasileiras, comparou a qualidade de vida entre cidades e gêneros, e investigou se o tempo de prática de TCC interfere na qualidade de vida. A amostra foi composta por 104 indivíduos (69 mulheres) que relataram praticar regularmente TCC no estilo Yang pelo menos duas vezes por semana por um período mínimo de três meses. Amostra com idade de 50,3 $\pm 15,4$ anos, com tempo de prática de 74,8 $\pm 50,3$ meses. Os participantes foram classificados nas categorias iniciante (3-12 meses; $\mathrm{n}=42)$, intermediário (12-24 meses; $\mathrm{n}=17$ ) e avançado (> 24 meses; $\mathrm{n}=45$ ). Os participantes responderam ao questionário Short Form Health Survey (SF-36) (versão em português) para obter uma medida de qualidade de vida. Com base nos resultados, os praticantes foram classificados no SF-36 nas categorias "bom" e "muito bom", com maiores escores para homens vs mulheres. Os escores de qualidade de vida foram semelhantes entre praticantes de todos os níveis e entre cidades. O domínio saúde que obteve o maior escore geral foi a capacidade funcional com 89,42 $\pm 12,21$, e o menor foi o estado geral de saúde com $66,94 \pm 18,08$. Este resultado é corroborado pela literatura científica internacional, com ênfase na qualidade de vida dos-praticantes regulares.

Palavras-chave: tai chi chuan, qualidade de vida, práticas integrativas complementares. 


\section{INTRODUCTION}

Tai Chi Chuan (TCC) is considered by ancient masters as a universal Chinese treasure. It is originally a martial art style that involves physical abilities such as balance, strength, flexibility, speed, motor coordination and agility [1]. This martial art has become a popular fitness exercise worldwide [2] and has been practiced by people of all ages for therapeutic purposes in order to improve both physical and mental functions due to the growing increase in scientific research highlighting its numerous benefits $[1,2]$.

Benefits of TCC practice have been reported for prevention of falls in the elderly, osteoarthritis, Parkinson's disease, chronic obstructive pulmonary disease (COPD), cognitive functioning, depression, cardiac rehabilitation, stroke rehabilitation, dementia among other diseases or dysfunctions [3, 4, 5, 6]. According to Kong et al. (2016) [7], TCC is described as meditation in movement, combining concentration and mindfulness, being able to modulate various aspects of health such as mood, functions of the immune and autonomic nervous system.

In Brazil, the supportive scientific evidence along with the increasing TCC popularity has contributed to its current insertion in the complementary integrative practices of the Brazilian Unified Health System. Demand for TCC practice in Brazil increased 46\% between 2017 and 2018 [8].

A common factor in studies that investigated TCC benefits $[9,10,11]$ is the contribution to improve the practitioner's quality of life, which is defined by The World Health Organization (1995) [12] as "an individual's perception of their position in life in the context of the culture and value system in which they live and in relation to their goals, expectations, standards, and concerns". Therefore, the improvement in TCC practitioner's quality of life arises due to a sum of psychosomatic and somatopsychic factors provided through the practice of art [5].

Although the benefits of TCC have been reported in different populations [10, 13], it is noteworthy to highlight that researches in Brazilian practitioners are scarce. Understanding the impact of TCC on quality of life in Brazilian practitioners may contribute with information to the management of TCC practices in the government health programs and reinforce the incentive to increase adherence in population. Furthermore, it is important to know the practitioner's life quality within his/her reality, its intrinsic and extrinsic factors. Studies usually control the sample in a way that does not always match reality. Not only should they consider novice practitioners, which will obtain neurophysiological gains by practicing TCC regularly for three months, contributing positively to their life quality, but also consider intermediate and advanced practitioners.

Therefore, the present study aimed to analyze the quality of life in TCC practitioners in several Brazilian cities, to compare the quality of life among cities and between genders, and to investigate if the practice time of TCC interferes with the quality of life.

\section{MATERIALS AND METHODS}

This was a descriptive observational and ex post facto study. The sample consisted of 104 individuals (69 women) who reported regularly practice Yang style TCC at least twice a week for a minimum period of three months. We chose this style because it is the most popular in Brazil, with approximately 540 practitioners supervised by 18 instructors certified by the Brazilian Society of Tai Chu Chuan and Oriental Culture (SBTCC) [14]. The exclusion criteria were: refusal to give informed consent or refusal to answer any question of the quality of life questionnaire. Participants were recruited through their instructors. Previously, all 18 instructors identified via SBTCC were invited to contribute to the data collection. They were informed about the study aims and procedures and, after agreeing, they invited their students to participate in the study. Thus, our sample was intentionally selected from different cities/states of Brazil (Table 1). Sample aged 50.3 \pm 15.4 years old, with practice time of 74.8 \pm 50.3 months. Participants were classified as beginner (3-12 months; $\mathrm{n}=42)$, intermediate (12-24 months; $\mathrm{n}=17)$, and advanced ( $>24$ months; $\mathrm{n}=45)$. 
Table 1: Demographic characteristics of Yang style Tai Chi Chuan Brazilian practitioners.

\begin{tabular}{cccccc}
\hline Region & State & City & N & City HDI & State HDI \\
\hline \multirow{2}{*}{ Northeast } & Bahia & Ilhéus & 5 & 0.690 & 0.660 \\
& Sergipe & Aracaju & 17 & 0.770 & 0.665 \\
& & São Paulo & 15 & 0.805 & \\
\multirow{5}{*}{ Southeast } & São Paulo & $\begin{array}{c}\text { Bauru } \\
\text { Ribeirão Preto }\end{array}$ & 9 & 0.801 & 0.783 \\
& Rio de Janeiro & Rio de Janeiro & 4 & 0.800 & 0.799 \\
& Minas Gerais & Uberlândia & 20 & 0.789 & 0.761 \\
& & & & & 0.731 \\
\multirow{2}{*}{ South } & Rio Grande do Sul & Canoas & 9 & 0.750 & 0.746 \\
& Santa Catarina & Joinville & 15 & 0.809 & 0.774 \\
\hline
\end{tabular}

Note: HDI: Human Development Index (IBGE, 2020) [15].

Participants answered the Short Form Health Survey (SF-36) questionnaire (Portuguese version) [16] to obtain a measure of quality of life. Briefly, SF-36 is composed of 36 items, with two to six response options for each item, evaluating eight distinct health concepts or domains: functional capacity; physical aspects; ache; general health status; vitality; social aspects; emotional aspects, and mental health. Rating scores of each domain range from 0 (worst possible health) to 100 (best possible health). Higher value represents greater satisfaction with quality of life. Previously, after the end of a class, participants were oriented about and familiarized with the SF-36 questionnaire by their respective teachers. Then, immediately before the following class, they were asked to fulfill the printed SF-36. So, data about each health domain were recorded to further analysis. Using SF36 is suggested for application to a high number of practitioners [17].

This study was approved by the local Institutional Ethics Committee for Human Research (protocol n. 143.961). Moreover, study protocol followed Resolution 466/2012 of the National Health Council of Brazil. All participants provided written informed consent to participate in the study.

\section{Statistical Analysis}

The Shapiro-Wilk test $(p<0.05)$ was used to test the normality of the data, and parametric distribution was not found. Mann-Whitney test was used to compare the quality of life between genders, and Kruskal-Wallis test was used to compare the quality of life among groups (cities and practice time). All statistical analyzes were performed using SPSS, version 20.0 (IBM, USA). Statistical significance was set at $\mathrm{p} \leq 0.05$.

\section{RESULTS AND DISCUSSION}

Quality of life scores of participants are presented in Table 2 for each health domain.

Table 2: General score of individuals in the health domains.

\begin{tabular}{l|c|c|c|c}
\hline \multicolumn{1}{c}{ Health Domain } & Minimum & Maximum & Mean & Standard Deviation \\
\hline Functional capacity & 30 & 100 & 89.42 & 12.21 \\
Physical aspects & 0 & 100 & 86.30 & 26.27 \\
Ache & 32 & 100 & 75.26 & 17.67 \\
General Health Status & 0 & 100 & 66.94 & 18.08 \\
Vitality & 20 & 100 & 69.92 & 17.71 \\
Social aspects & 13 & 100 & 79.81 & 23.06 \\
Emotional Aspects & 0 & 100 & 80.13 & 33.34 \\
Mental health & 28 & 100 & 75.25 & 16.53 \\
\hline
\end{tabular}

Source: elaboration based on the data collected. 
The results of the Kruskal-Wallis test did not allow us to reject the null hypothesis of the test for cities and individuals' practice time when related to the health domains of the SF-36 questionnaire.

There was no significant difference when the quality of life was compared among the cities for each health domain evaluated: functional capacity $\left[\mathrm{x}^{2}(8)=6.109 ; \mathrm{p}=0.635\right]$; physical aspects $\left[\mathrm{x}^{2}\right.$ $(8)=8.167 ; \mathrm{p}=0.417] ;$ ache $\left[\mathrm{x}^{2}(8)=7.214 ; \mathrm{p}=0.514\right]$; general health status $\left[\mathrm{x}^{2}(8)=7.468 ; \mathrm{p}=\right.$ $0.487]$; vitality $\left[\mathrm{x}^{2}(8)=4.522 ; \mathrm{p}=0.807\right]$; social aspects $\left[\mathrm{x}^{2}(8)=4.880 ; \mathrm{p}=0.770\right]$; emotional aspects $\left[\mathrm{x}^{2}(8)=12.212 ; \mathrm{p}=0.142\right]$; mental health $\left[\mathrm{x}^{2}(8)=11.277 ; \mathrm{p}=0.187\right]$.

Regarding the practice time, there was also no significant difference among groups considering beginning, intermediate, and advanced practitioners: functional capacity $\left[\mathrm{x}^{2}(2)=2.886 ; \mathrm{p}=0.236\right]$; physical aspects $\left[\mathrm{x}^{2}(2)=0.333 ; \mathrm{p}=0.847\right]$; ache $\left[\mathrm{x}^{2}(2)=1.940 ; \mathrm{p}=0.379\right]$; general health status $\left[\mathrm{x}^{2}(2)=2.044 ; \mathrm{p}=0.360\right]$; vitality $\left[\mathrm{x}^{2}(2)=1.077 ; \mathrm{p}=0.583\right]$; social aspects $\left[\mathrm{x}^{2}(2)=3.872 ; \mathrm{p}=\right.$ $0.144]$; emotional aspects $\left[\mathrm{x}^{2}(2)=0.511 ; \mathrm{p}=0.774\right]$; mental health $\left[\mathrm{x}^{2}(2)=3.420 ; \mathrm{p}=0.181\right]$.

However, there was a statistically significant difference in some health domains according to gender (Table 3). It was observed that men presented higher quality of life scores for functional capacity, ache, general health status, vitality, and social aspects.

Table 3: Relationship of the factor gender with the health domains.

\begin{tabular}{|c|c|c|c|c|}
\hline \multirow{2}{*}{ Health domain } & \multicolumn{2}{|c|}{ Gender } & \multirow{2}{*}{$U$} & \multirow{2}{*}{$p$} \\
\hline & Female & Male & & \\
\hline Functional capacity & $47.09 \pm 13.6$ & $63.16 \pm 7.0$ & 834.50 & $0.009 *$ \\
\hline Physical aspects & $51.96 \pm 28.5$ & $53.56 \pm 21.2$ & 1170.50 & 0.750 \\
\hline Ache & $48.40 \pm 18.2$ & $60.59 \pm 15.5$ & 924.50 & $0.048 *$ \\
\hline General Health Status & $46.25 \pm 19.4$ & $64.83 \pm 11.7$ & 776.00 & $0.003 *$ \\
\hline Vitality & $46.28 \pm 19.5$ & $64.76 \pm 9.7$ & 778.50 & $0.003 *$ \\
\hline Social aspects & $47.95 \pm 24.6$ & $61.47 \pm 17.5$ & 893.50 & $0.025^{*}$ \\
\hline Emotional Aspects & $51.10 \pm 34.6$ & $55.26 \pm 30.6$ & 1111.00 & 0.416 \\
\hline Mental health & $49.37 \pm 17.6$ & $58.67 \pm 13.52$ & 991.50 & 0.136 \\
\hline
\end{tabular}

Note: $\mathrm{U}=$ Manny-Whitney $\mathrm{U}$ test; *Statistically significative values for $\mathrm{p} \leq 0.05$.

As proposed in this study, we obtained an overview of these practitioners' quality of life and some interesting considerations. Based on the results, we could say that the practitioners obtained an average score in the health domains of the SF-36 questionnaire, classified as "good" and "very good" for generic quality of life. This classification was similar to that found in other studies [18, 19].

The quality of life scores observed in the present study were similar among beginner, intermediate, and advanced practitioners. Given that all participants reported minimally three months of practice, this result suggests that this period may be enough to provide benefits related to the quality of life. Moreover, the equivalent quality of life observed among cities may be explained by the fact that all instructors are certified by the Brazilian Society of Tai Chi Chuan and Oriental Culture (SBTCC) to teach Tai Chi Chuan Yang style. Then, all participants underwent classes conducted with the same methodology.

In the present study, the health domain that obtained the highest overall score was functional capacity with $89.42 \pm 12.21$, and the lowest was the general health status with $66.94 \pm 18.08$. These results were similar to those of Liu et al. (2019) [18], who performed a 24-week intervention. As for the development of physical abilities through Tai Chi Chuan practice, described by Zou et al. (2017) [1], we expected that the regular practitioner had a good score in the functional capacity domain. In general health, the questions are more general and TCC practice would only be a factor given the complexity that makes up an individual's health.

Statistically significant differences occurred in the relationship between health domains and the factor gender. The males had better results than females in the following health domains: functional capacity; ache; general health status; vitality, and social aspects. Based on the average age of 50.3 \pm 15.4 years old of the sample, it is necessary to consider that, at this age, women may have symptoms of climacteric and menopause, as it was showed by Hoga et al. (2015) [20]. Such symptoms cause hormonal changes that may lead to a detrimental influence on domains women 
had relatively lower scores than men. However, caution should be taken when interpreting these data since several other factors, not controlled in this study, may interfere with this result.

Increasingly, TCC practice has been spreading across the country. Practitioners who took part in study sample were from different regions: south, southeast, and northeast of Brazil. Notoriously, there is greater participation of female practitioners. One of the possible explanations for the dissemination of this martial art throughout the country, according to the Brazilian Society of Tai Chi Chuan and Oriental Culture (SBTCC), is the ease of access to information, both by the practitioner who arouses the interest in practicing it, by the instructor who can teach, as well as the health professional who recommends the practice according to the patient's needs. These characteristics can also be one of the justifications for the mean age of the sample, who search for personal interest or medical recommendation.

A recent study highlighted improvements induced by the practice of TCC for functionality and quality of life in patients with primary total knee arthroplasty due to knee osteoarthritis [21]. The emphasis was on the physical aspects and mental health of the SF-36 questionnaire when compared with the results of the research control group. Kim, Kim and Lee (2015) [22] also found improvements in practice, specifically in stroke patients, in five out of eight domains: physical capacity, ache, vitality, general health status, and mental health. Therefore, these results strengthen its dissemination to the health area as a therapeutic resource. This efficient resource can be inserted in programs that serve the Brazilian population, as it is already inserted in the integrative practices of SUS.

However, considering the minimum value results found for physical aspects, general health status, and emotional aspects, some individual cases need an additional therapeutic resource to practice TCC, be it physical or psychological, to achieve good scores in these domains. There is nothing to prevent the association of this practice with other therapeutic resources. As suggested by Qin et al. (2019) [23] in recent meta-analysis, both the practice of TCC alone or as an additional therapy associated with physical therapy can decrease pain and improve disability in patients with low back pain. Meta-analysis studies [6, 17, 24, 25, 26, 27] reinforce scientific evidence of TCC.

Finally, there is a trend of studies on TCC practice to improve quality of life in cancer patients $[18,24,26,27]$. They also include a decrease in fatigue and cortisol levels and increased immune function in cancer patients. The existing results and perspectives are more secure so that the practice becomes increasingly accessible to this public.

Despite our study have been conducted with adult participants, other authors also showed improvements in quality of life in other samples as asthmatic children [28, 29, 30]. Therefore, a new perspective, based on data from this current sample and other studies mentioned here $[1,17]$ with TCC practitioners, may give rise to the misconception of thinking that this martial art is exclusively recommended for adults or the elderly when this is not true. TCC can be practiced by any age and can positively influence any person's quality of life.

Cross-sectional design and absence of a control group are limitations of the present study, which limits us to state that the TCC can interfere positively with the quality of life of practitioners. However, our results suggest that the TCC practitioners showed high scores for quality of life. Further researches should investigate the effect of TCC programs on quality of life, physical fitness, and capacity functional.

\section{CONCLUSION}

We concluded that the Tai Chi Chuan practitioners' quality of life in cities in Brazil is classified between good and very good. This is corroborated by international scientific literature, with emphasis on the regular practitioners' quality of life. Regarding gender comparison, males had a better quality of life than women considering the functional capacity, ache, general health status, vitality, and social aspects. However, the practice time and the city where Tai Chu Chuan classes were conducted did not interfere with the quality of life scores. We reiterate that the promotion of Tai Chi Chuan should be encouraged in the population so that more people can enjoy the benefits of this practice. 


\section{BIBLIOGRAPHIC REFERENCES}

1. Zou L, Wang H, Xiao Z, et al. Tai chi for health benefits in patients with multiple sclerosis: A systematic review. PLoS One. 2017 Feb;12(2):e0170212, doi:10.1371/journal.pone.0170212.

2. Guo J, Shen Y, Li B, et al. Does Tai Chi Chuan improve psychological well-being and quality of life in patients with breast cancer? Protocol for a systematic review of randomized controlled trials: A Protocol for Systematic Review and Meta-Analysis. Medicine. 2020;99(16):e19681, doi:10.1097/MD.0000000000019681.

3. Hochberg MC, Altman RD, April KT, et al. American College of Rheumatology 2012 recommendations for the use of nonpharmacologic and pharmacologic therapies in osteoarthritis of the hand, hip, and knee. Arthritis Care Res. 2012;64(4):465-474, doi:10.1002/acr.21596.

4. Wang C, Iversen MD, McAlindon T, et al. Assessing the comparative effectiveness of Tai Chi versus physical therapy for knee osteoarthritis: design and rationale for a randomized trial. BMC Complement Altern Med. 2014;14:333, doi:10.1186/1472-6882-14-333.

5. Huston P, McFarlane B. Health benefits of tai chi: What is the evidence? Can Fam Physician. 2016;62(11):881-890.

6. Huang ZG, Feng YH, Li YH, Lv CS. Systematic review and meta-analysis: Tai Chi for preventing falls in older adults. BMJ Open. 2017 Feb;7(2):e013661, doi:10.1136/bmjopen-2016-013661

7. Kong LJ, Lauche R, Klose P, et al. Tai Chi for Chronic Pain Conditions: A Systematic Review and Metaanalysis of Randomized Controlled Trials. Sci Rep. 2016;6:25325, doi:10.1038/srep25325

8. Brasil. Ministério da Saúde. Cresce $46 \%$ procura por Práticas Integrativas Complementares no SUS [Internet]. 2019 Mar 15 [updated 2019 Mar 15; accessed 2020 Mar 09]. Available from: https://www.gov.br/saude/pt-br/assuntos/noticias/cresce-46-procura-por-praticas-integrativas-no-sus-2.

9. Song R, Grabowska W, Park M, et al. The impact of Tai Chi and Qigong mind-body exercises on motor and non-motor function and quality of life in Parkinson's disease: a systematic review and metaanalysis. Parkinsonism Relat Disord. 2017;41:3-13, doi:10.1016/j.parkreldis.2017.05.019.

10. Hao Y, Zhang L, Zhang Z, Chen L, He N, Zhu S. Tai Chi exercise and functional electrical stimulation of lower limb muscles for rehabilitation in older adults with chronic systolic heart failure: a nonrandomized clinical trial. Braz J Med Biol Res. 2019;52(12):e8786, doi:10.1590/1414-431X20198786

11. Liu J, Yu P, Lv W, Wang X. The 24-form Tai Chi improves anxiety and depression and upregulates mir17-92 in coronary heart disease patients after percutaneous coronary intervention. Front Physiol. 2020 Mar;11:149, doi:10.3389/fphys.2020.00149.

12. The World Health Organization Quality of Life assessment (WHOQOL): position paper from the World Health Organization. Soc Sci Med. 1995;41(10):1403-1409, doi:10.1016/0277-9536(95)00112-k.

13. Wayne PM, Lee MS, Novakowski J, et al. Tai Chi and Qigong for cancer-related symptoms and quality of life: a systematic review and meta-analysis. J Cancer Surviv. 2018;12(2):256-267, doi:10.1007/s11764-017-0665-5.

14. Sociedade Brasileira de Tai Chi Chuan e Cultura Oriental (SBTCC) [Internet]. [accessed 2020 May 29]. Available from: http://www.sbtcc.org.br/.

15. Instituto Brasileiro de Geografia e Estatística (IBGE) [Internet]. [accessed 2020 May 29]. Available from: https://cidades.ibge.gov.br/.

16. de Soárez PC, Kowalski CC, Ferraz MB, Ciconelli RM. Tradução para português brasileiro e validação de um questionário de avaliação de produtividade [Translation into Brazilian Portuguese and validation of the Work Limitations Questionnaire]. Rev Panam Salud Publica. 2007;22(1):21-28, doi:10.1590/s1020-49892007000600003.

17. Castro PC, Tahara N, Rebelatto JR, Driusso P, Aveiro MC, Oishi J. Influência da universidade aberta da terceira idade (UATI) e do programa de revitalização (REVT) sobre a qualidade de vida de adultos de meia-idade e idosos. Rev Bras Fisioter. 2007 Dec;11(6):461-467, doi:10.1590/S141335552007000600007.

18. Liu X, Williams G, Kostner K, Brown WJ. The Effect of t'ai chi on Quality of Life in Centrally Obese Adults with Depression. J Altern Complement Med. 2019;25(10):1005-1008, doi:10.1089/acm.2019.0050

19. Ni X, Chan RJ, Yates P, Hu W, Huang X, Lou Y. The effects of Tai Chi on quality of life of cancer survivors: a systematic review and meta-analysis. Support Care Cancer. 2019;27(10):3701-3716, doi:10.1007/s00520-019-04911-0.

20. Hoga L, Rodolpho J, Gonçalves B, Quirino B. Women's experience of menopause: a systematic review of qualitative evidence. JBI Database System Rev Implement Rep. 2015 Sep;13(8):250-337, doi:10.11124/jbisrir-2015-1948. 
21. Li L, Cheng S, Wang G, Duan G, Zhang Y. Tai chi chuan exercises improve functional outcomes and quality of life in patients with primary total knee arthroplasty due to knee osteoarthritis. Complement Ther Clin Pract. 2019;35:121-125, doi:10.1016/j.ctcp.2019.02.003

22. Kim H, Kim YL, Lee SM. Effects of therapeutic Tai Chi on balance, gait, and quality of life in chronic stroke patients. Int J Rehabil Res. 2015;38(2):156-161, doi:10.1097/MRR.0000000000000103.

23. Qin J, Zhang Y, Wu L, et al. Effect of Tai Chi alone or as additional therapy on low back pain: Systematic review and meta-analysis of randomized controlled trials. Medicine. 2019;98(37):e17099, doi:10.1097/MD.0000000000017099.

24.Zeng Y, Luo T, Xie H, Huang M, Cheng AS. Health benefits of qigong or tai chi for cancer patients: a systematic review and meta-analyses. Complement Ther Med. 2014;22(1):173-186, doi:10.1016/j.ctim.2013.11.010.

25. Song S, Yu J, Ruan Y, Liu X, Xiu L, Yue X. Ameliorative effects of Tai Chi on cancer-related fatigue: a meta-analysis of randomized controlled trials. Support Care Cancer. 2018;26(7):2091-2102, doi:10.1007/s00520-018-4136-y.

26.Zou L, Yeung A, Li C, et al. Effects of Meditative Movements on Major Depressive Disorder: A Systematic Review and Meta-Analysis of Randomized Controlled Trials. J Clin Med. 2018 Aug;7(8):195, doi: $10.3390 / \mathrm{jcm} 7080195$.

27. Murley B, Haas B, Hermanns M, Wang YT, Stocks E. Influence of Tai Chi on Self-Efficacy, Quality of life, and fatigue among patients with cancer receiving chemotherapy: a pilot study brief. J Holist Nurs. 2019;37(4):354-363, doi:10.1177/0898010119867557.

28. Chang YF, Yang YH, Chen CC, Chiang BL. Tai Chi Chuan training improves the pulmonary function of asthmatic children. J Microbiol Immunol Infect. 2008;41(1):88-95.

29. Lin HC, Lin HP, Yu HH, et al. Tai-Chi-Chuan exercise improves pulmonary function and decreases exhaled nitric oxide level in both asthmatic and nonasthmatic children and improves quality of life in children with asthma. Evid Based Complement Alternat Med. 2017;2017:6287642, doi: $10.1155 / 2017 / 6287642$

30. Liao SJ, Chong MC, Tan MP, Chua YP. Tai Chi with music improves quality of life among communitydwelling older persons with mild to moderate depressive symptoms: A cluster randomized controlled trial. Geriatr Nurs. 2019;40(2):154-159, doi:10.1016/j.gerinurse.2018.08.001 